\title{
The Universe as a Computer Game, from Virtual to Actual Reality
}

\author{
ALFRED DRIESSEN \\ University of Twente, Enschede, Netherlands \\ Driessen.Alfred@gmail.com \\ ORCID: 0000-0002-7901-4020
}

\begin{abstract}
From the very beginning of ancient Greek philosophy up to the present day a puzzling correlation is found between rationality and reality. In this study this relation is examined with emphasis on the philosophical tradition of Aristotle and Aquinas. A comparison is made with the virtual reality created by computers and actual reality of our universe. The view expressed in the scientific neopositivism of Jordan and Mach is found to be an adequate approach to avoid contradictions in the interpretation of modern physics. A challenging hypothesis is made by updating the Laplacian Demon by a powerful creative intellect in line with Judeo-Christian tradition. With this hypothesis a new light is shed on several fundamental issues in modern science.
\end{abstract}

Keywords: Philosophy of Science; Hylomorphism; Aristotle; Aquinas; Creation; Rationality.

\section{Introduction}

It is a puzzling idea that parts of reality, or even the whole universe, can be related to a rational processes in a computer (see e.g. Lloyd 2013), or in an intelligent being. As an introduction one may consider the three following examples. 
The French mathematician and philosopher Laplace (1790-1799) was intrigued by recent progress in the knowledge of the laws that determine the orbits of the planets within our solar system. With these laws and careful calculations it was possible to predict the movement of the planets for the future and also for the past. In order to clarify the philosophical consequences he performed what later would be called a Gedanken experiment. He introduced a superior spirit with unlimited processing-power and unlimited knowledge of the state of the universe: the demon of Laplace (Laplace 1814).

We have to consider the actual state of the universe as the effect of its previous state, and as the cause of the state that will follow. Imagine an intelligent being which, at a certain time, would know all the forces at work in nature, and the respective location of all the beings that compose it. If it were powerful enough to analyze these data, it could embrace together in the same formula the movements of the largest bodies of the universe and those of the lightest atom. Nothing would be uncertain for this intelligent being and both, the future and the past would be present to its eyes. The human mind offers, with the perfection it gave to astronomy, a small idea of this intelligence. Its discoveries in the fields of mechanics and geometry, together with that of universal gravitation, now enable it to understand in the same analytical expressions the present and future states of the system of the world.

As a consequence, the universe is ruled by strict determinism. Once the system in any moment of the past is known in principle with infinite precision, the future is completely determined. Today are serious doubts whether the reasoning can still be applied in the light of the results of modern physics (see e.g. Hawking 1999; Läuffer 1997), but the basic idea is worthwhile to retain. There is strong correlation between on the one hand what an intellect, in this case the Laplace demon, can calculate and predict and on the other hand, reality.

For a second example one could consider the Game of Life. This Cellular Automaton is the work of the mathematician John Conway in 1970. It is described by (Gardner 1970): 
Because of its analogies with the rise, fall and alternations of a society of living organisms, it belongs to a growing class of what are called "simulation games" - games that resemble real-life processes.

The Game of Life is based on four rules, that create in a deterministic way certain structures on a computer screen. Depending on the initial distribution of living cells, the final outcome can be frozen structures or just a completely empty screen. In other cases rapidly changing structures appear, some with a periodic behavior. The game is played on a two-dimensional array, like an infinite chess-board. The rules are simple enough to play with the aid of a pencil and a piece of paper, but the full capacity of the game is most easily assessed by implementing the rules in a computer and observe the evolution on a display. The rules are as follows:

1. Any live cell with fewer than two live neighbours dies, as if by loneliness.

2. Any live cell with more than three live neighbours dies, as if by overcrowding.

3. Any live cell with two or three live neighbours lives, unchanged, to the next generation.

4. Any dead cell with exactly three live neighbours comes to life.

Once the starting condition is known, i.e. the initial distribution of live cell on the infinite chessboard, the rest is a matter of applying rule 1 to 4 in a loop. With an extremely powerful computer, ideally a Turing machine, the final structures would instantaneously be known.

For the third example I refer to a very stimulating conversation with Paul Davies in the nineteens of the past century. Speaking about his current work and ideas, he mentioned that already as a student he was deeply impressed by an insight: one could predict the trajectory of a cannonball just by a brief calculation on the backside of an envelope.

In all the three examples a basic idea seems to apply. Just by intellectual activity (by a demon, a human mind or a computer) the temporal evolution of the physical reality can be in part or even completely explained. The question now arises whether this is just a happy coincidence or that one 
could look for an ontological basis. What is the relation between material reality and intellectual activity? And, if there is a causal relation, how can the step from intellectual activity to reality be made? How can intellectual activity lead to something so evidently material as our real world? Stephen Hawking expresses in lyric words this fundamental question (Hawking 1988):

Even if there is only one possible unified theory, it is just a set of rules and equations. What is it that breathes fire into the equations and makes a universe for them to describe?

For a further discussion of this quote, see (Driessen 1995).

\section{An astonishing parallelism between old and new concepts}

\subsection{Matter and form}

Classic philosophy already was puzzled by the close relation between intellectual activity and material reality. In the beautiful allegory of the cave, Plato relates the material world to the invisible world of the ideas (Plato 380 BC). And ideas suppose intellectual activity. Aristotle made a step further in stating that material things, being physically one, are metaphysically composed by two principles: the (philosophical) matter and the form which informs the matter. Both, matter as well as form are not beings on their own but are principles of being. For the ideas of Plato, which in a certain way laid the basis for the Aristotelian forms, this appears to be less evident. The ideas are the primary reality whereas the things we observe are only shadows of the eternal world of ideas. When dealing with the highest form, the Unmoved Mover (Aristotle Metaphysics Book XII), Aristotle makes an exception. The Unmoved Mover is an existing intellectual being acting as the origin of all reality, not just a principle of being. In the following we restrict the discussion to material objects where Aristotle observes the metaphysical structure of matter and form. We will not consider the case of beings with a spiritual dimension, like human beings or the just mentioned Unmoved Mover. 
In his philosophical analysis, Aristotle mentioned the work of Democritus, see, e.g. (Berryman 2016). This philosopher introduced the atoms to make changes intelligible in order to solve the antinomy of the philosophy of Parmenides. It is by pure geometrical dynamical arrangements of the atoms that the different objects of the observable world are constituted. Here one finds already the germ of the metaphysical structure of things: atoms and arrangement. Aristotle unified the approach of both of his predecessors by introducing a subtlety: matter (the atoms of Democritus) and form (the ideas of Plato) are only philosophical principles, not objects of reality on their own. For Plato, the immaterial ideas were elements of reality, whereas the material world was considered as shadows referring to these ideas. For Democritus the atoms were already elements of reality and geometry was responsible for the apparent richness in diversity of material objects. Considering the concrete material beings as objects of reality, Aristotle seems to be more in accordance with common sense experience in comparison with Platonic and modern idealism. In contrast to the approach of Democritus, the unity of beings becomes more intelligible. Not the constituent parts are real but the whole, whereas Democritus allows only for an aggregate of particles, i.e. the atoms. The approach of Aristotle is called hylomorphism: material beings are the result of a form (Greek morphe, Latin forma) that informs a certain matter (Greek hyle, Latin materia).

The relevance of this approach seems to be quite restricted. In fact, in modern studies about the foundation of science and specially physics not often mention is made of this great discovery of the fundamental metaphysical structure in physical objects. An exception is Schrödinger, one of the founding fathers of Quantum Mechanics, (Schrödinger 1954). In the present study the author hopefully is able to show that this approach would provide an adequate philosophical basis to make modern science intelligible and, simultaneously, to let it appear conform to common sense experience. In two recent studies the Aristotelian approach is applied to the field of quantum biology (Driessen 2015) and to complexity (Driessen 2016). 
In modern science and technology the concepts of matter and form as the metaphysical co-principles of real beings revive in a new setting. This, of course, is completely unexpected by the Greek philosophers. The form, can be considered as information implemented in a suitable matter, or in computer terms as software implemented in a certain hardware. Philosophers, like Leonardo Polo, already referred to this parallelism while speaking about biological evolution (Polo 1993).

If we would make a revision of the evolution within a philosophical perspective, we would see that one could consider the genetic code as a formal cause. The rediscovery of the formal cause points to a foundation in presence. And information science is also a theory of formal cause. And as one applies this to material objects, it is a theory of hylomorphism, with other words, it is completely Aristotelian. Within information science there are causes in actu, otherwise there would be no message.

In the following the parallelism between Aristotelian based philosophy and information science is deepened. So one may observe that similar to the Aristotelian forms, there is no standalone software. It has always to be implemented in some hardware. For example, a document has to be on an optical disk, displayed on a screen, stored on a USB-memory or any other hardware medium. On the other hand, hardware, matter in Aristotelian terms, always has a certain form or information, a meaningful code, only 0's or only 1's or just a random bit pattern. One has to emphasize that in this context hardware has to be "switched-on" hardware. Only combinations of hard- and software occur in the real world of information technology, and similarly real objects in our visible world consist of informed matter and never just of standalone matter or standalone forms.

Table 1 gives an overview how the different philosophical systems follow the Aristotelian approach, or how they just avoid it. It is a simplification but it shows that the way of considering the co-principles matter and form is a really relevant characteristic of a philosophical system. 
Table 1. Matter and form in different philosophical approaches

\begin{tabular}{|l|l|l|l|l|}
\hline Philosopher & $\begin{array}{l}\text { Co-principle } \\
\text { matter is } \\
\text { related to: }\end{array}$ & $\begin{array}{l}\text { Co-principle } \\
\text { form is } \\
\text { related to: }\end{array}$ & What is primary & $\begin{array}{l}\text { Matter- } \\
\text { form } \\
\text { structure }\end{array}$ \\
\hline $\begin{array}{l}\text { Democritus, } \\
\text { atomists }\end{array}$ & atoms & $\begin{array}{l}\text { pure } \\
\text { geometry }\end{array}$ & atoms & weak \\
\hline Plato, idealists & shadow & idea & idea & weak \\
\hline $\begin{array}{l}\text { Aristotle, } \\
\text { realists }\end{array}$ & matter & $\begin{array}{l}\text { form, } \\
\text { information }\end{array}$ & $\begin{array}{l}\text { the thing, i.e. } \\
\text { informed matter }\end{array}$ & strong \\
\hline materialists & matter & $\begin{array}{l}\text { chance, } \\
\text { natural law }\end{array}$ & matter & weak \\
\hline $\begin{array}{l}\text { computer } \\
\text { scientists }\end{array}$ & hardware & software & $\begin{array}{l}\text { software implement- } \\
\text { ted in hardware }\end{array}$ & strong \\
\hline
\end{tabular}

\subsection{Potentia and actus}

In the philosophy of Aristotle and Aquinas the correlated concepts potentia and actus play a central role. Potentia could be translated by possibility and can be defined as having the possibility to be actual (potentia ad actum). What is a logical possibility can become eventually an ontological reality. But let's focus again on the computer game paradigm.

In computer language one speaks often about virtual reality, i.e. a computer-generated scenery which for some of our senses appears as reality. If one, for example, installs a racing game on a computer, the cars on the screen have a very weak reality: they are just an array of rapidly changing colored pixels generated by the computer code. In addition, it does not matter whether the colored pixels are displayed by an LED-screen or an old-fashioned cathode ray tube display. But the experience of reality can be such that the learning effect for pilots on a flight simulator allows drastic reduction on expensive real-life flight hours.

The question is, how to arrive from virtual reality to actual reality. We can, of course, work on still more sophisticated means to satisfy the need 
of our senses. In certain way extend the concept of hi-fi (high-fidelity) of audio systems to the other senses and create for humans a virtual reality, only with difficulties distinguishable from reality. In this way one can, perhaps at least emotionally, be fully immersed in this created reality; but objectively it remains virtual or apparent reality.

One can also consider the paradigm of the creativity of an architect. He designs an office building and works it out in a number of detail drawings with all dimensional and technical details, including the materials to be used for the construction. Nowadays the plans would result in a code that can generate an interactive virtual space. The customers are allowed to enter the building within the virtual space and visit all rooms and getting the impression of the building in its finished state. But the building is still an idea, even if the design is so completely worked out, that a construction company could realize it without any intervention of the architect. Once the architectural instructions being implemented according to the design in the desired materials, the office building will be a reality. One has to keep in mind that the creativity of the architect is restricted to the transformation of already existing materials, i.e. it is restricted to the formal aspects. These whole of formal aspects is the output of the design work. It can be contained in drawings, software, a scale-model, or oral instructions, but it is something, with economic value that can be traded like any other intellectual property (IP) or patent.

One may say that creation of information or the formal aspects are in a certain way always related to an intellectual activity. Mariano Artigas explains (Artigas 2002):

I used to say that information is "materialized rationality." It includes plans that are stored in spatio-temporal structures. It guides the successive formation of increasingly complex patterns. Information is stored, displayed, integrated, coded and decoded in the different natural systems and processes.

The formal aspects, which are related to potential realities, however, have to be implemented in materials or matter in order to arrive at reality in the full meaning of the word. Once again one can observe that the old concepts 
of hylomorphism with identifying matter and form as the constituent parts of beings can be applied to modern concepts like hardware and software. It also helps to understand human creativity and related concepts like intellectual property.

It the case of an architect or other creative professionals we understand how to arrive from virtual to factual reality. This is possible by transformation of existing materials by an agent. But how to arrive more in general from a virtual world to full reality? With the terminology of Aristotle and Aquinas one could ask how one could arrive from the possibility of being to actual being. There is first the demand of absence of any internal contradiction in the formal aspects, like, e.g., the impossibility of a square circle. There should be an objective possibility that what not yet is a being, eventually may exist. Aquinas speaks of the potentia logica. This is a necessary condition for arriving at the actual existence but not a sufficient one. More is needed, firstly another potentia, the potentia realis, the possibility to receive the substantial form containing all the determination and information about the thing that should become a reality. This kind of potentia is philosophically called materia prima, the first matter (Elders 1982). Secondly an agent, being in actu, should inform the (philosophical) matter with the substantial form. Using computer language one could say that an agent is needed who implements the software in suitable hardware. Materia prima and substantial form are philosophical concepts, co-principles of beings; but they are no beings on their own. In contrast herewith, in the example of the architect, matter like bricks and wood have its own being. They are already existing.

\subsection{Matter in science and matter in philosophy}

Going back to the computer game paradigm, information has first to fulfill the demand of being without contradiction, with other words the code should not lead to contradictory results for the implementation in hardware. For example when representing the code in a hardware device like a memory stick, either a "0" or " 1 " should be allowed, and no other not defined state. Only then the code would fulfil the demands of what above we called the potentia logica. 
The potentia realis, prime matter, is known to be a principle of being, but not a being on its own. Hardware and bricks are being on its own, but what is known about prime matter? Aristotle introduced the co-principles matter and form to make changes in the material world intelligible. He observed that in any change of beings something remains and something changes. From this he arrived at the metaphysical structure of the material beings: matter (the remaining) and form (the changing). Many philosophers of the past and the present follow a different way of argumentation. In the present study, however, no attempt is made to reproduce the deep discussion in the literature on philosophical matter. Instead, a proposition is made in the following.

By analogy with the architect one should look for a creative intellect, but now gifted with an additional power. This intellect not only transforms matter but is able to implement his ideas in matter without the need of transformation of existing materials. This powerful intellect would create material objects but never stand-alone matter. Any physical material is already informed matter, that i.e. material with certain properties. In modern physics it is obvious that even the vacuum, the empty space, is something. It is described by a certain gravitational or electro-magnetic field with a certain energy density. Our universe is finite, with no border. There is not something like an empty space outside our cosmos, or better said, it is not meaningful to ask a question about this: it is a 'Scheinproblem', something that has the appearance (Schein) only of a problem. The reason is that in the question already wrong or dubious assumptions are made. In this particular case, for example, space is assumed to be a reality on its own, whereas Aristotle and modern physics agree that it is only a mental construction with restricted validity. Later we will deal in more detail with 'Scheinprobleme".

With philosophical means alone, it is difficult to grasp completely the existence and nature of the creational intellect and to understand its creational activity. But on the other hand it is equally, and perhaps even more difficult to find a rational argument for excluding the possibility of its existence. In this context it is worthwhile to consider divine revelation as an additional source for a deeper understanding of creation. In this special 
case, one may follow the Judeo-Christian tradition that for more than 2500 years has fertilized philosophical and scientific thinking. In the first phrase of the central book of this tradition, the Bible, one finds (Gen., 1: 1): In the beginning God created heaven and earth. Accepting this statement as being true, the philosopher may proceed in his understanding of reality: there is a creative intellect who is responsible for all reality, the immaterial (heaven) as well the material beings (earth). The first phrase of the gospel of St. John confirms explicitly the rational character of the creator: En arche en ho logos; in the beginning was the Word (John, 1: 1), or alternatively translated, in the beginning was the Logos, the Ratio, as Benedictus XVI emphasizes in his address in Regensburg (Benedictus XVI 2006).

\section{From the Laplace demon to the knowledge of the creative intellect}

In this section two approaches are brought together. The first is the generalized computer game approach, which is a kind of extension of Conway's game of life. There one finds an intelligent being, in this case a mathematician, who defines a set of rules and implements them on a computer. As a result, output is generated on a computer screen that resembles in certain sense real-life dynamic structures: virtual reality. The second approach is to update the Laplace demon to a powerful, creative intellect.

The intuition of Laplace expresses a fundamental insight: the reality of our world is closely related to the intellectual activity of an intellect. But reality is much richer than the philosophical preferences of Laplace allow for. Common sense opinions of the time of Laplace are expressed in the slogan Liberté, Égalité, Fraternité of the French Revolution. The first motto is without any meaning if there was no free will for humans. The demon of Laplace, however, reduces freedom to an inner experience without any influence on the material world. To him, only strictly deterministic laws seem to govern nature. Since the arise of Quantum Mechanics, about a century ago, we know better, as science encountered non-deterministic laws of nature. A recent study even states concerning free will (Suarez 2015): 
Both, quantum nonlocal correlations and relativistic local ones, assume "free will" on the part of the experimenter.

Before continuing it seems to be necessary to sketch briefly the subtle relations between reality one the one side with the human intellect and on the other side with the creative intellect. For this aim a summary is given of the approach of Aquinas, who applies Aristotelian hylomorphism to the philosophy of knowledge. There is extended literature about this field of philosophy, sometimes called Gnoseology or Epistemology (Llano 2001; Nguyen 2015). According to Aquinas, one could start with the Unmoved Mover or First Cause. Evidently, the concept "cause" employed in classical Aristotelian-Thomistic philosophy has a richer meaning than currently used in literature. Today "cause" is narrowed mostly to events correlated in time, like one can see in the quotation of Laplace in section 1. In order to understand properly "First Cause", one has to think of the first actor or author, where first relates to a hierarchy of causes acting not only from the past but also from the present or even from outside time. First Cause exceeds the restricted performance of the demon of Laplace; it is a powerful and creative intellect. Just by knowing beings as real he creates in the same act these beings. This is not only a static process as if creating refers to a point back in time. Instead it appears that the continuously present action of First Cause remains necessary for the created reality. This creative intellect supports and enables from outside time, all dynamic interactions, the evolution in time and the operation of second causes like men's free will.

Let's go back to Conway game of life. Here the complete dynamics is contained in four rules. By applying these rules and the starting distribution of living cell on the two-dimensional matrix, all resulting evolutionary patterns are completely determined. For a Turing machine or a sufficient powerful intellect these patterns are immediately known, once the starting condition are settled. Now consider the creative intellect which has all the properties of First Cause. This intellect generates all relevant rules for reality and other information (the forms of Aristotle) to end up eventually in in the creation of reality. With this we are still following the paradigm of 
a computer game. In computer games the output is eventually implemented as information displayed on a screen. One has to remember that according to hylomorphism, information (the form) is implemented in (philosophical) matter in order to arrive at a real being. It is not matter that is created but informed matter. For this creational activity the powerful intellect needs only his creative power of his intellectual activity. It is creation ex nihilo, out of nothing instead of transformation of already existing material. Besides this strict creational activity of the First Cause, one finds in nature transformations and events where other causes (secondary causes) interfere including man's free will. Even in the rudimentary game of life, one can generate patterns like Gosper's Glider Gun that generates stabile dynamic patterns, the gliders. In this case, one should consider the running computer as first cause and the Glider Gun as secondary cause; both of course are deterministic in this peculiar case.

In the approach of Aquinas, human knowledge is nothing more than assessing part of this enormous knowledge of the powerful intellect. In computer terms one could say we are able to decipher some subroutines of the great game. The demon of Laplace, for example, just learned to deal with classical mechanics. This is true knowledge, but only valid within some restriction we know now more in detail thanks to our current state of physics.

Aquinas explains the process of human knowledge in philosophical terms by applying hylomorphism. As all information is contained in the form and not the (philosophical) matter, the problem is how to receive the form in the intellect. If man intends to get knowledge of an object, metaphysically composed of matter and form, his senses collect the information (the form) and abstracts increasingly the material components of the object in question. If one looks, for example, at a great oak in front of one's window, the lens of the eye generates an upside down picture of the tree on the retina. Obviously the material component has been largely reduced, but the image is still materially present as chemical changes in the light-sensitive cells of the retina. There is image-processing in different stages of the transmission of the information of the retina cells to the brain. In the brain, certain patterns are formed. Up to now all processes are carried out by humans as well as 
higher animals, because the final stage has not been reached where the information is completely abstracted from matter. This is possible only in the human mind. In order to receive and process information without any material component evidently a non-material, spiritual capacity is needed, in our example the mind. Once the information about the oak, the form, is received by the mind it can now be implemented, not in matter (that would consist in duplicating in certain sense the oak), but in the mind. The mind becomes intentionally the tree, as Aquinas calls this specific presence. (Lisska 2016). The amount of information (or the extension of the subroutine in the computer paradigm) depends of the state of knowledge of the person involved. Most recognize the form of leaves, can predict the acorns appearing in fall and the coloring of the leaves, or know that it is hard wood suitable for furniture. But only few specialist know in detail the cell structure or the complex light-induced chemical processes in the leaves. This intentional presence in the human mind is not a duplication of the tree, as the matter of the oak has now completely been abstracted. And what is needed for a duplicate is informed matter; the form is just 'information' about the thing, not the thing an sich (on itself).

It is worthwhile to quote Anthony Lisska in order to summarize the distinction between esse naturale and esse intentionale (Lisska 2016, p. 145):

It is through the sense impression in the faculty that the sense faculty 'becomes' the sense object in the external world, but immaterially or intentionally. The same form is exemplified 'intentionally' in the faculty and 'existentionally' in the object; this is the Aristotelian insight further enhanced by Aquinas. There is an identity of form, one in esse intentionale and the other in esse naturale, indicating the two modes of exemplification utilized. Without this identity of structure rendered possible by the two modes of exemplification, the isomorphism of mind and reality in Aristotelian ontology and philosophy of mind would be impossible.

The Aristotelian-Aquinas approach could seem to be unnecessary complex or requiring too many assumptions. Among others the assumption of a non-material aspects in the human minds is not generally accepted. But the alternatives ask perhaps even more belief and imagination. 
In the following some examples are given where the generalized computer game approach (based on Aristotle and Aquinas) sheds new light on several important issues in the philosophy of science.

\section{Neopositivism and why is there no ether?}

There is an interesting article of Pascual Jordan about Ernst Mach and the neopositivism (Jordan 1972), see also (Beiglböck 2007) for a brief discussion. After emphasizing that he does not consider the original form of positivism of Comte, Jordan explains that the neopositivism of Mach has a new significance especially for physicist. In his argumentation he starts with an observation often made by physics teachers: "We know only the effect of electricity, but the nature of electricity remains unknown." He considers this as a Scheinproblem, something that has the appearance of a problem, appearing only as a problem, without being, however, a real problem. Jordan follows the approach of Mach and states that a question about the nature of electricity is irrelevant, if one expects something beyond the physical effects of electricity. The reason for this is that any answer that experimentally can be checked is dealing only with the effects of electricity and not with its nature. Applying Maxwell's equation to moving charges one gets electromagnetic waves. In the case of waves at the beach it is known what is periodically going up and down. It is just the local level of water. In electromagnetic waves it is the electrical field. What is that? There is only an operational definition: if one puts a charge in this periodic changing field one experiences a periodically changing force. Any quest for more information is meaningless. There is no need to go beyond the four Maxwell equation.

It is known that Maxwell and other great physicists tried to find mechanical models for understanding more about the nature of electricity or other phenomena. One may quote the famous statement of Lord Kelvin expressing a way of thinking still blocking the understanding of $20^{\text {th }}$ century physics (Kelvin 1884): 
I can never satisfy myself until I can make a mechanical model of a thing. If I can make a mechanical model, I can understand it.

The most prominent approach to tackle the electro-magnetic Scheinproblem has been the ether model. It is an attempt to go beyond Maxwell equations in order to find a reality that materializes in some way the notion of fields that vary in place and time. Michelson, and after him many others, designed beautiful experiments and did extremely accurate measurements. But it became more and more evident that there is no ether. There is no (mechanical) model that would reveal a deeper reality. This reality is counterintuitive only for someone who considers reality in a mechanistic view: the world as a gigantic and extremely complex mechanical watch. This view can also be found in popular works, like the blind watchmaker (Dawkins 1986).

If one accepts the generalized computer game approach the question about a possible ether becomes evidently a 'Scheinproblem'. With the four Maxwell equation all classical electro-magnetic problems can be solved and verified by experiments. Why look further when the basic equations of this part of the computer game are already fully understood. The problem arises only, if one is not satisfied with information or any other non-material reality as the sufficient cause for reality. Then, of course, one could be in contradiction with one's own philosophical assumptions.

Jordan mentions another example where a 'Scheinproblem' arises in physics. Consider the hydrogen atom: an electron circulating around a proton. There seems to be a strong parallelism with the motion of a planet around the sun. One still can admire the Atomium left in Brussels after the world exposition of 1956. But what about Maxwell: a circulating charge like the electron should act as an antenna and emit radiation. This energy-loss due to radiation should diminish within short time the rotational frequency and lead to a collapse of the atom. But looking more carefully for the physical laws, one discovers that these are not dealing with localized particles, but with wavefunctions. The square of this function is an indication of the probability to find the electron at a certain place. All experiments up to now confirm the correctness of the theoretical picture. Grammatical 
correct questions, like where is the electron in the hydrogen atom, cannot be answered by the physicists. And this is not because of lack of knowledge about the system. Nature or better said, reality, does not contain information about the position of the electron, but only about the probability to find it at a certain place. Or, say it more challenging: the assumption that there is an electron in a hydrogen atom is not completely correct. There is in reality only the hydrogen atom; the constituents parts, however, the proton and electron are only potentially present (in potentia). Only strong enough external causes, e.g. strong radiation or heat, may reduce the atom to its constituents parts, for a more detailed discussion see (Driessen 2015).

\section{A challenging hypothesis}

In the foregoing we considered a daring assumption: all reality is the consequence of the acting of a great powerful creative intellect. His or her (and not its, because an intellect is always a person) thinking is creative thinking. If he knows information as implemented in matter, things are created including their interaction and the performance as secondary cause. Being caused could mean being caused in a deterministic way, but also only with a certain probability or even involving liberty as in the case of human beings. In fact, this powerful intellect takes account of granting freedom of choice in its creation.

Once again one could compare the powerful creative intellect with the architect. As long as the design of the building is only in its mind, there is pure information. By talking about this, making a drawing and let it be built by a construction company, it becomes increasingly a reality implemented in matter. The powerful intellect does not need to work out his ideas, just by considering them as implemented in matter or informing matter, they are real.

Like Laplace one could start: Imagine an intelligent being: but now the capacity of this intellect is largely extended: imagine a creative intellect who is creator in the most strict meaning of the word of all reality. To make it clear, in the foregoing no attempt has been made to give a scientific proof of 
the existence of this creative intellect. But there is also no scientific reason to exclude this. Why not accept the existence of the creative intelligent being without further proof as a working hypothesis? It could be worthwhile, as a new and coherent view is made possible on a number of fundamental issues in the foundation of science.

The wondering of the young Paul Davies about the correlation between some calculations on a sheet of paper can now easily be explained. He is performing just a subroutine of the great computer code. Similarly, the observation of Einstein becomes evident: Das ewig Unbegreifliche an der Welt ist ihre Begreiflichkeit. (The eternal un-understandable of the world is its intelligibility), quotation of Einstein in (Fokker 1955). The rationality of nature is not any more a surprise.

There is another issue that for Einstein was of primary importance. This is his famous statement (Einstein 1926, see also Hawking 1999):

Quantum mechanics is certainly imposing. But an inner voice tells me that it is not yet the real thing. The theory says a lot, but does not really bring us any closer to the secret of the 'Old One'. I, at any rate, am convinced that He does not throw dice.“

What did he mean by The Old One (God) does not throw dice. Evidently not that someone in heaven has certain preferences in ways of entertainment. The context of this sentence refers to a quite serious metaphysical statement on the probabilistic nature of the laws of Quantum Mechanics. It means that at the end, at the highest level of reality, there should be no randomness. With our hypothesis, the intuition of Einstein can be easily reconciled with a probabilistic character of the laws of nature. As mentioned already before, there can be a hierarchy of causes. There are observables causes related to the laws of the nature which may be probabilistic, but there may be other, non-observable causes at a higher level. Being non-observable by any physical means, they are evidently not subjected to natural laws. One could think of First cause, the human free will or perhaps other causes related to beings with a spiritual dimension (see, e.g. Driessen and Suarez 1997). These non-observable causes could intervene in the causation of effects for which 
the laws of physics could provide only a certain probability. Respecting the probabilistic laws of physics they could nevertheless determine that a certain event is taking place here and now.

Just a brief remark about hidden variables. These are physical parameters that are unknown to our present state of knowledge of the universe or even are in principle not accessible. But they belong to the realm of science. First Cause and other non-observable causes, however, are transcending the material reality and are, as such, not hidden variables. The statement that should be made is that physics, or more generally natural science, is not complete. There are others actors influencing the material world, like human free will, or First Cause. Our argumentation is quite speculative, but nevertheless worthwhile to be seriously considered. A summary on different views on completeness of physics can be found in (Vicente 2006).

\section{Conclusion}

In the foregoing the computer game paradigm has been applied to reality. In addition the Laplace demon has been updated to be a powerful creative intellect knowing, among others, $20^{\text {th }}$ century physics (and beyond). This article, however, is primarily an intent to apply the philosophy of Aristotle and Aquinas to exploit the relation between intellectual activity and reality. The examples of modern physics are given to demonstrate that without a well-developed metaphysics the observed phenomena remain weird or strange. The intention was to stimulate new ways of thinking about reality and to show the astonishing actuality of the classical philosophical approach of Aristotle and Aquinas.

By accepting or just postulating the existence and intervention of a powerful creative intellect, astonishing pieces of reality end up in a coherent, meaningful puzzle. One could mention the following:

- The prominent role of information in our view of the cosmos becomes evident.

- The characteristics of the two great theories of the $20^{\text {th }}$ century, Quantum Mechanics, could lose part of their weirdness. 
- The classification of certain scientific problems, as Scheinprobleme, as occurred in the neo-positivism of Mach and Jordan, is confirmed as being adequate.

- The rationality of our world, so astonishing for Einstein, becomes evident.

- The view of the Judeo-Christian tradition regarding the creation of the universe obtains an astonishing actuality.

- In addition one could remark that it is worthwhile to study the concepts of metaphysics as, according to De Broglie (1947):

Science frequently ends up engaging in metaphysics without realizing it, and this is not exactly the safest way of doing metaphysics.

As said before the existence of the powerful creative intellect has not been proven in this article. But in science there is the Popper approach of falsification of a theory widely accepted (Popper 1959). As far as it is known to me there are up to now no conclusive arguments or proofs regarding the falsification of the existence of a powerful creative intellect at the origin of our universe and the causation of non-observable causes in present spatial-temporal events. On the other hand, in this study also no falsification of alternative approaches are given. The reason for this is, that the acceptance or not acceptance of a creative intellect cannot be based on strictly physical or scientific arguments (Naturwissenschaften). For this one enters the realm of philosophy (Geisteswissenschaften).

\section{References}

Aristotle, Metaphysics, book XII.

Artigas, Mariano. 2002. "The Mind of the Universe: Understanding Science and Religion." In Faith, Scholarship, and Culture in the 21st Century, edited by Alice Ramos and Marie I. George, 113-125. Washington D.C.: The Catholic University of America Press.

Beiglböck, Wolf, D. 2007. "Ernst Pascual Jordan als Autor wissenschaftlicher und allgemeinbildender Schriften." In Pascual Jordan (1902-1980) Mainzer Symposium zum 100. Geburtstag. Max Planck Institute for the History of Science. Preprint 329. 
Benedictus XVI. 2006. Address at the University of Regensburg, 12.09.2006.

Berryman, Sylvia. 2016. “Democritus.” In Stanford Encyclopedia of Philosophy, https:// plato.stanford.edu/entries/democritus/

Dawkins, Richard. 1986. The blind watchmaker. New York: Norton \& Company, Inc.

De Broglie, Louis. 1947. "Au dela des mouvantes limites de la science.” Revue de metaphysique et de morale, 3:278.

Driessen, Alfred. 1995. "The question of the existence of God in the book of Stephen Hawking, A brief history of time.” Acta Philosophica 4:83-93.

Driessen, Alfred and Suarez, Antoine. 1997. "Introduction” and "Final Remarks". In Mathematical Undecidability, Quantum Nonlocality and the Question of the Existence of God, edited by Alfred Driessen and Antoine Suarez, Springer (Kluwer).

Driessen, Alfred. 2015. “Life and Quantum Biology, an Interdisciplinary Approach.” Acta Philosophica 24:69-86.

Driessen, Alfred. 2016. "The Role of Philosophy as a Guide in Complex Scientific and Technological Processes.” http://philsci-archive.pitt.edu/12446/

Elders, Leo J. 1982. De Metafysica van St. Thomas van Aquino in historisch perspectief. Tabor Brugge, p. 158. For the English translation: The Metaphysics of Being of St. Thomas Aquinas: In a Historical Perspective. Brill, Leiden, New York, Köln, 1993. Einstein, Albert. 1926. Letter to Max Born.

Fokker, Adriaan D. 1955. “Albert Einstein, 14 maart 1978-18 april 1955.” Nederlands Tijdschrift voor Natuurkunde, 21:125-129.

Gardner, Martin. 1970. "Mathematical Games, The fantastic combinations of John Conway’s new solitaire game ‘life’.” Scientific American 223 4:120-123.

Hawking, Stephen. 1988. A brief history of time, from the big bang to black holes. New York: Bantam Books.

Hawking, Stephen. 1999. Does God play Dice? Lecture, published on http://www. hawking.org.uk/does-god-play-dice.html

Jordan, Pascal. 1972: "Neopositivismus und physikalische Erkenntnistheorie“. In Erkenntnis und Besinnung. Oldenburg: Stalling Verlag.

Kelvin, Lord. 1884. Baltimore Lectures on Molecular Dynamics and the Wave Theory of Light (1884 and printed 1904), see also http://todayinsci.com/K/Kelvin_Lord/ KelvinLord-Quotations.htm

Laplace, Pierre Simon. 1814. Essai philosophique sur les probabilités. Gauthiers-Villars: Paris, 1921, p. 3.

Laeuffer, Jacques. 1997. "Scientism and Scientific Knowledge of Things and God.” In Mathematical Undecidability, Quantum Nonlocality and the Question of the Existence of God, edited by Alfred Driessen and Antoine Suarez, 185-191. Springer (Kluwer). 
Lisska, Anthony, J. 2016. Aquinas's Theory of Perception: An Analytic Reconstruction. Oxford: Oxford University Press.

Llano, Alejandro. 2001. Gnoseology. Manila: Sinag-Tala Publishers Inc.

Lloyd, Seth, 2013. The universe as quantum computer. arXiv:1312.4455.

Nguyen, Knut Vuong. 2015. "Gnoseology: In Relation to Truth, Knowledge and Metaphysics.” PhilPapers, http://philpapers.org/rec/NGUGIR.

Plato. 380 BC. The Republic, book VII.

Polo, Leonardo. 1993. Presente y Futuro del Hombre. 13, Madrid: Ediciones Rialp.

Popper, Karl R. 1959. The Logic of Scientific Discovery. Oxford: Routlegde Classics.

Schrödinger, Erwin. 1954. Nature and the Greeks. Cambridge: Cambridge University Press.

Suarez, Antoine. 2015. Unified description of quantum nonlocal and relativistic local correlations: Both assume 'free will' and happen without connection in space-time. arXiv:1510.01312v1, 3 Oct. 2015.

Vicente, Agustin. 2006. “On the Causal Completeness of Physics.” International Studies in the Philosophy of Science 20:149-171. 